\title{
Effects of Minimal Extracorporeal Circulation on the Systemic Inflammatory Response and the Need for Transfusion after Coronary Bypass Grafting Surgery
}

\author{
Mehmet Emre Elçi, ${ }^{1}$ Aydın Kahraman, ${ }^{1}$ Emre Mutlu $\mathbb{D}^{1},{ }^{2}$ and Cemil Selim İspir ${ }^{3}$ \\ ${ }^{1}$ Siyami Ersek Education and Research Hospital, Department of Cardiovascular Surgery, Istanbul, Turkey \\ ${ }^{2}$ The Ministry of Justice, Council of Forensic Medicine, İstanbul, Turkey \\ ${ }^{3}$ Marmara University, Faculty of Medicine, Cardiovascular Surgery, İstanbul, Turkey
}

Correspondence should be addressed to Emre Mutlu; dremremutlu@yahoo.com

Received 29 July 2018; Revised 10 February 2019; Accepted 11 April 2019; Published 4 June 2019

Academic Editor: David J. Chambers

Copyright (c) 2019 Mehmet Emre Elçi et al. This is an open access article distributed under the Creative Commons Attribution License, which permits unrestricted use, distribution, and reproduction in any medium, provided the original work is properly cited.

\begin{abstract}
Objectives. The aim of this study is to compare the effects of the minimal extracorporeal circulation (MiECT) on postoperative systemic inflammatory response and the need for transfusion in patients undergoing open heart surgery with cardiopulmonary bypass. Methods. Patients were divided into two groups; Group M $(n=31)$ included the patients operated via using the MiECT system and Group C $(n=27)$ included the patients operated via using conventional cardiopulmonary bypass $(\mathrm{CPB})$. Perioperative markers of inflammation after cardiopulmonary bypass in both groups were tested by measuring the levels via chemiluminescent immunometric assay. Blood samples were taken consecutively after anesthesia induction, $30^{\text {th }}$ minute of CPB, on the $6^{\text {th }}, 24^{\text {th }}$, and $48^{\text {th }}$ hours after cardiopulmonary bypass. Results. The mean amount of priming solution was significantly lower in Group M when compared to Group C $(802.60 \pm 48.26$ and $1603.71 \pm 49.85 \mathrm{ml})$. The mean hematocrit $(\mathrm{Hct})$ value taken immediately after cardiopulmonary bypass was found to be significantly higher in the MiECT patients with respect to the other group (\% $32.71 \pm 3.98$ and $\% 28.82 \pm 4.39$ ). The transfused amounts of erythrocyte suspension and fresh frozen plasma were found to be significantly lower in patients in Group M when compared to those in Group C. Postoperative mediastinal drainage was also significantly lower in patients in Group $M$ with respect to the other group. There was no significant difference between markers of inflammation. Conclusion. Our results show that MiECT seems to be more advantageous in terms of priming volume, perioperative hematocrit levels, need for blood and blood product transfusion, and mediastinal drainage with respect to the conventional approach after coronary artery bypass grafting.
\end{abstract}

\section{Introduction}

Cardiopulmonary bypass $(\mathrm{CPB})$ is defined as a technique that temporarily replaces the function of the heart and lungs during cardiac surgery, maintaining the circulation of blood and the oxygen content of the body $[1,2]$. The main principle of cardiopulmonary bypass is that venous blood is drained into the reservoir and passes through the oxygenator, through an arterial filter, and back into the patient.

Leukocytes, endothelial cells, and platelets are activated due to contact of the blood with foreign surfaces during cardiopulmonary bypass [3-6]. It is known that the systemic inflammatory response leads to postoperative morbidity and mortality. The resulting inflammatory response plays a primary role in the pathogenesis of cardiac, pulmonary, renal, hepatic, neurological, and hemostatic complications following cardiopulmonary bypass. The severity of inflammatory response during and after cardiopulmonary bypass can be reduced by increasing the biocompatibility of extracorporeal systems, by using filtration techniques, by using anti-inflammatory pharmacological agents, by using antioxidants, and by thermoregulation techniques.

In recent years, efforts have accelerated in order to reduce this inflammatory response. In this context, standard 
cardiopulmonary bypass systems have been modified to reduce the surface areas of extracorporeal circuits. Completely closed circuits have been developed to lower the volume of the prime solution for reducing hemodilution $[7,8]$ One of the newest technologies in this regard is CPB circuits called the minimal extracorporeal circulation system (MiECT) [9-11] Reducing the contact surface area and priming CPB systems with lower volumes have been shown to reduce the severity of the inflammatory response at certain rates $[12,13]$.

The minimal extracorporeal circulatory system consists of a centrifugal pump, a membrane oxygenator, a short heparin-coated line, and a vacuum line that can be added if necessary $[14,15]$. The venous reservoir and the standard vacuum line in the conventional cardiopulmonary bypass system are not present in this circuit. Blood from the venous system does not accumulate in any area. It is a completely closed circuit that is not air related. This means that blood elements are exposed to less contact surface area and activity is kept at a lower level. The absence of a venous reservoir and the shorter length of the lines allow the prime volume used to be reduced as well.

The aim of our study was to compare the effects of minimal extracorporeal circulation system and conventional cardiopulmonary bypass circuits on postoperative transfusion requirement and inflammatory response. CRP, proinflammatory cytokines (IL-6, IL-8), TNF- $\alpha$, and neutrophil elastase were used for assessing the inflammatory response.

\section{Materials and Methods}

In order to reduce the need for postcardiopulmonary bypass transfusion and the systemic inflammatory response in patients treated in the Department of Cardiovascular Surgery of Marmara University Faculty of Medicine, a singleblind, prospective, randomized trial using minimal extracorporeal circulation circuits was planned. The study was approved by the MUTF Research Ethics Committee (Protocol number: 09.2013.0218). All patients were informed in detail about the study. The consent form was signed by the patient and the researcher.

2.1. Patient Selection. The study included 58 consecutive patients who underwent cardiopulmonary bypass and isolated coronary artery bypass surgery between March and December 2013 by the Cardiovascular Surgery Clinic at Marmara University Faculty of Medicine. The MiECT system had an extra cost. Accordingly, we kept the number at 20. We did an equal number of control groups. Demographic data of the patients are given in Table 1 .

Exclusion criteria: patients who read the information form but did not give consent, who underwent urgent surgery, who had a known malignancy, who had preoperative infection, who had low preoperative renal functions (preoperative serum creatinine level $>1.2 \mathrm{mg} / \mathrm{dl}$ ), who had preoperative liver disease (having abnormal liver function tests), who had preoperative ejection fraction $<40 \%$, and who received preoperative intra-aortic balloon pump (IABP) support or inotropic drugs were not included in the study.

Because it was thought that interleukin-6,interleukin8,TNF-alpha, and neutrophil elastase levels might be effective, patients who had any systemic infection and suspected systemic infection (white blood cell count $\geq 10,000$, sedimentation rate $\geq 10 \mathrm{~mm} / \mathrm{h}$, and C-reactive protein level $\geq 5 \mathrm{mg} / \mathrm{L}$ ) were excluded from the study. In addition, patients who received antibiotics within the last 15 days for any reason, who received steroids antibiotics within the last 15 days for any reason, who had unstable angina and preoperative myocardial injury (elevated levels of troponin and CK-MB), who underwent additional procedures due to intraoperative complications (heart injury, aortic dissection, vein injury, arterial injury, etc.), and who were under the age of 18 years were excluded from the study.

The patients were randomly divided into two groups: minimal extracorporeal circulation system (Group M, $n: 31$ ) and conventional cardiopulmonary bypass system (Group C, $n: 27)$. Except for the cardiopulmonary bypass system used, the same anesthesia and surgical techniques were applied in both groups.

\subsection{Cardiopulmonary Bypass and Surgical Technique.} During cardiopulmonary bypass, perfusion was achieved with a roller pump (Sorin Group, Italy) in Group C and with a centrifugal pump (Maquet Jostra AG Group, Germany) in Group M. In Group C, hollow-fiber membrane oxygenator (DidecoR Compactflo Evo Phisio, Sorin Group, Italy) and arterial filter (DidecoR, Sorin Group, Italy) were used. In Group M, heparin-coated membrane oxygenator (Quadrox-i Adult, Jostra AG, Germany) was used. While 1/ $2 \times 3 / 32$ inch venous and $3 / 8 \times 3 / 32$ inch arterial polyvinyl chloride lines were used in Group C, 3/8 ×3/32 inch heparin-coated venous and arterial lines were used in Group M. The total prime volume was $1650 \mathrm{ml}(1000 \mathrm{ml}$ Isolyte S, $500 \mathrm{ml}$ Gelofusine, and $150 \mathrm{ml}$ Mannitol) in Group C and $800 \mathrm{ml}(500 \mathrm{ml}$ Isolyte $\mathrm{S}$ and $300 \mathrm{ml}$ Gelofusine) in Group $M$, respectively. In this group, retrograde autologous priming was performed after cannulation, and this volume was taken back before CPB. Both groups also underwent nonpulsatile cardiopulmonary bypass. All patients received cefazolin sodium $1 \mathrm{~g}$ before performing an incision.

All operations were performed with standard median sternotomy. The left internal mammary artery (IMA) was used for revascularization of the left anterior descending artery (LAD). The great saphenous vein of appropriate length removed on the right or left lower extremity was used for revascularization of the other vessels. After the pericard was opened and suspended, $300 \mathrm{U} / \mathrm{kg}$ of heparin sodium was administered to Group C and $150 \mathrm{U} / \mathrm{kg}$ of heparin sodium was administered to Group M. An additional dose of heparin was administered so that the activated coagulation time was $>400$ seconds in Group C and between 250 and 300 seconds in Group M during CPB. The arterial flow was measured by aortic cannula (20-22-24 Fr according to the patient's BSA) (Cal MedR Lab, California, USA) placed in the ascending 
TABLE 1: Baseline characteristics of the patient groups.

\begin{tabular}{|c|c|c|c|c|c|}
\hline & & & Group C & Group M & $P$ \\
\hline Age & & $($ mean $\pm S D)$ & $60.25 \pm 10.08$ & $63.29 \pm 8.52$ & $P=0.61$ \\
\hline \multirow{2}{*}{ Sex } & Female & $(n / \%)$ & $6 \pm 22.20 \%$ & $4 \pm 12.90 \%$ & \multirow{2}{*}{$P=0.56$} \\
\hline & Male & $(n / \%)$ & $21 \pm 77.80 \%$ & $27 \pm 87.10 \%$ & \\
\hline Weight (kg) & & $($ mean $\pm S D)$ & $167.14 \pm 5.70$ & $171.03 \pm 6.65$ & $P=0.45$ \\
\hline Height $(\mathrm{cm})$ & & $($ mean $\pm S D)$ & $73.44 \pm 11.20$ & $81.58 \pm 11.31$ & $P=0.77$ \\
\hline $\mathrm{EF} \%$ & & $($ mean $\pm S D)$ & $54.37 \pm 9.19$ & $56.51 \pm 8.75$ & $P=0.35$ \\
\hline Euroscore II\% & & $($ mean $\pm S D)$ & $1.72 \pm 1.01$ & $1.65 \pm 0.82$ & $P=0.49$ \\
\hline \multirow{2}{*}{ CCS } & $1^{*} 2$ & $(n / \%)$ & $23 \pm 83.7 \%$ & $26 \pm 81.8 \%$ & \multirow{2}{*}{$P=0.67$} \\
\hline & $3 * 4$ & $(n / \%)$ & $4 \pm 17.3 \%$ & $5 \pm 19.2 \%$ & \\
\hline \multirow{2}{*}{ NYHA } & $1^{*} 2$ & $(n / \%)$ & $24 \pm 88.9 \%$ & $27 \pm 87.1 \%$ & \multirow{2}{*}{$P=0.29$} \\
\hline & $3^{*} 4$ & $(n / \%)$ & $3 \pm 11.1 \%$ & $4 \pm 12.9 \%$ & \\
\hline $\mathrm{DM}$ & & $(n / \%)$ & $15 \pm 55.6 \%$ & $15 \pm 48.4 \%$ & $P=0.15$ \\
\hline $\mathrm{HT}$ & & $(n / \%)$ & $24 \pm 88.9 \%$ & $25 \pm 80.6 \%$ & $P=0.38$ \\
\hline Hyperlipidemia & & $(n / \%)$ & $12 \pm 44.4 \%$ & $10 \pm 33.2 \%$ & $P=0.25$ \\
\hline Smoking & & $(n / \%)$ & $20 \pm 74.1 \%$ & $22 \pm 71 \%$ & $P=0.75$ \\
\hline Alcohol & & $(n / \%)$ & $1 \pm 3.2 \%$ & $1 \pm 3.7 \%$ & $P=0.54$ \\
\hline
\end{tabular}

CCS: Canadian Cardiovascular Society; NYHA: New York Heart Association classification; CPB: cardiopulmonary bypass; EF: ejection fraction; DM: diabetes mellitus; HT: hypertension; SD: standard deviation.

aorta. Because the diameters of the lines of the two systems placed in the right atrium of the patients were different, venous return was achieved with two-stage venous cannula (36/46-36/50 Fr) (Cal MedR Lab, California, USA) in Group $\mathrm{C}$ and with two-stage venous cannula (32/36-32/40 Fr) (Maquet, Jostra AG Group, Germany) in Group M. After the cannula was placed in the ascending aorta for cardioplegia and vent, $\mathrm{CPB}$ was performed. During the operations, while moderate systemic hypothermia $\left(28-32^{\circ} \mathrm{C}\right)$ was used in Group C, superficial hypothermia $\left(28-32^{\circ} \mathrm{C}\right)$ was used in Group M. After the clamp was placed in the ascending aorta, cardiac arrest was achieved with an antegrade delivery of $10 \mathrm{~mL} / \mathrm{kg}$ of blood cardioplegia (plegisol +30 meq potassium chloride $+10 \mathrm{meq}$ sodium bicarbonate- $1 / 4$ ) at $5-7^{\circ} \mathrm{C}$ by applying a pressure of $120-140 \mathrm{mmHg}$ in Group $\mathrm{C}$ and with an antegrade delivery of $10 \mathrm{~mL} / \mathrm{kg}$ of blood cardioplegia ( 40 meq potassium chloride +10 meq magnesium sulphate +10 meq sodium bicarbonate) at the pump's heat by applying a pressure of $120-140 \mathrm{mmHg}$ in Group M. Maintenance cardioplegia was delivered antegradely from the aortic root or grafts every 20 minutes.

The following points have been taken into consideration when deciding for blood transfusion in these patients: (1) the patient's anemia strengthening power, (2) the speed of ongoing bleeding, (3) the possibility of further blood loss, and (4) the risk of organ ischemia. Clinical parameters taken into consideration when deciding for blood transfusion are as follows: (1) age, (2) signs and symptoms of blood loss, (3) speed of blood loss, (4) cardiac function, (5) lung function, (6) ischemic heart disease, and (7) pharmacological treatment.

2.3. Follow-Up and Measurements. Arterial blood samples were collected from all patients after induction of anesthesia, 30 minutes after the onset of $\mathrm{CPB}$, and 6,24 , and 48 hours after termination of CPB for measuring IL-6, IL-8, TNFalpha, and neutrophil elastase.
IL-6, IL-8, TNF-alpha, and neutrophil elastase levels were measured using solid-phase, 2-site chemiluminescent immunometric assay commercial kits on the "Immulite 2000 XPi immunoassay system" device (Siemens Healthcare Diagnostic Products Ltd. Llanberis, Gwynedd LL55 4EL, United Kingdom) compatible with these kits. The CRP level was measured by the immunoturbidimetric method using commercial kits (CRPLX from Roche Diagnostics) on the "COBAS INTEGRA 800 analyzer" device (Roche Diagnostics GmbH, D-68298 Mannheim) compatible with these kits. All tests were made in accordance with the manufacturer's instructions.

2.4. Statistical Analysis. Mean, standard deviation, frequency, and ratio values were used for the descriptive statistics of the data. The distribution of the data was tested with the Kolmogorov-Smirnov test. The equality of the variants of the variables was tested. The $t$-test was used for the analysis of parametric data. The Mann-Whitney $U$ test was used for the analysis of nonparametric data. The paired sample $t$-test was used for repeated measures. The chisquared test was used for the analysis of proportional data. The Fisher's exact test was used when chi-squared test assumptions were not met. The SPSS 22.0 program was used for the analysis of the data.

\section{Results}

3.1. Perioperative Data of Patients. The perioperative data of the 58 patients included in the study are shown in Table 1. The mean number of bypass grafts was $3.25 \pm 0.81$ in Group $\mathrm{C}$ and $2.58 \pm 0.71$ in Group $\mathrm{M}$, respectively $(p>0.05)$. The mean cross-clamp time was $35.74 \pm 11.49 \mathrm{~min}$ in Group C and $36.41 \pm 9.41 \mathrm{~min}$ in Group M, respectively. The mean duration of CPB was $84.92 \pm 19.75 \mathrm{~min}$ in Group C and $85.55 \pm 20.56 \mathrm{~min}$ in Group M, respectively. There was no statistically significant difference between the two groups in 
terms of mean cross-clamp time and mean duration of CPB $(p>0.05)$ (Table 1$)$. The mean prime volume was $1603.71 \pm 49.85 \mathrm{ml}$ in Group $\mathrm{C}$ and $802.60 \pm 48.26 \mathrm{ml}$ in Group $M$, respectively. There was a statistically significant difference between the two groups in terms of mean prime volume $(p<0.05)$. The average amount of cardioplegic solution was $898.14 \pm 169.37 \mathrm{ml}$ in Group $\mathrm{C}$ and $558.06 \pm 114.81 \mathrm{ml}$ in Group $\mathrm{M}$, respectively. There was a statistically significant difference between the two groups in terms of average amount of cardioplegic solution $(p<0.05)$. The mean body temperature during $\mathrm{CPB}$ was $31.59 \pm 1.80^{\circ} \mathrm{C}$ in Group C and $34.01 \pm 0.042^{\circ} \mathrm{C}$ in Group M, respectively. There was a statistically significant difference between the two groups in terms of mean body temperature $(p<0.05)$.

3.2. Postoperative Data of Patients. The postoperative parameters of the patients are shown in Table 2. The mean amount of drainage from chest tubes was $672.22 \pm 157.09 \mathrm{ml}$ in Group C and 446.77 $\pm 134.12 \mathrm{ml}$ in Group M, respectively. There was a statistically significant difference between the two groups in terms of the mean amount of drainage from chest tubes $(p<0.05)$.

Although there was no statistically significant difference between the two groups in terms of hospital and intensive care unit length of stay, the mean duration of ventilation was $10.46 \pm 1.83$ hours in Group $C$ and $6.21 \pm 1.73$ hours in Group $M$, respectively. There was a statistically significant difference between the two groups in terms of mean duration of ventilation $(p<0.05)$.

We evaluated perioperative blood transfusion rates. The mean perioperative erythrocyte suspension (ES) transfusion was $1.70 \pm 0.66 \mathrm{U}$ in Group C and $0.93 \pm 0.89 \mathrm{U}$ in Group M, respectively. There was a statistically significant difference between the two groups in terms of mean perioperative ES transfusion $(p<0.001)$. Similarly, the mean perioperative FFP transfusion was $2.51 \pm 1.05 \mathrm{U}$ in Group $\mathrm{C}$ and $0.93 \pm 1.14 \mathrm{U}$ in Group $\mathrm{M}$, respectively. There was a statistically significant difference between the two groups in terms of mean perioperative FFP transfusion $(p<0.05)$. However, there was no statistically significant difference between the two groups in terms of mean perioperative platelet suspension (PS) transfusion $(p>0.05)$.

The preoperative and postoperative Hct values of the patients are shown in Table 3. There was no statistically significant difference between the two groups in terms of mean preoperative Hct value. The mean Hct value after leaving CPB was $28.82 \pm 4.39$ in Group C and $32.71 \pm 3.98$ in Group M, respectively. The mean Hct value at 24 hours postoperatively was $27.64 \pm 4.27$ in Group C and $31.9 \pm 4.65$ in Group M, respectively. There was a statistically significant difference between the two groups in terms of mean Hct value after leaving $\mathrm{CPB}$ and mean Hct value at 24 hours postoperatively $(p<0.05)$ (Table 4$)$.

3.3. C-Reactive Protein Levels. There was no statistically significant difference between the two groups in terms of mean CRP values at 24 and 48 hours postoperatively $(p>0.05)$ (Table 5).
3.4. Interleukin-6 Levels. There was no statistically significant difference between the two groups in terms of mean IL6 values before surgery, at $30 \mathrm{~min}$ of $\mathrm{CPB}$, and at 6,24 , and 48 hours postoperatively $(p>0.05)$ (Table 6).

3.5. Interleukin-8 Levels. There was no statistically significant difference between the two groups in terms of mean IL8 values before surgery, at $30 \mathrm{~min}$ of $\mathrm{CPB}$, and at 6,24 , and 48 hours postoperatively $(p>0.05)$ (Table 7$)$.

3.6. TNF- $\alpha$ Levels. There was no statistically significant difference between the two groups in terms of mean TNF- $\alpha$ levels $(p>0.05)$ (Table 8$)$.

3.7. Neutrophil Elastase Levels. There was no statistically significant difference between the two groups in terms of mean neutrophil elastase levels values before surgery, at 30 min of $\mathrm{CPB}$, and at 6,24 , and 48 hours postoperatively $(p>0.05)$ (Table 9).

\section{Discussion}

The heart-lung machine is an excellent device that makes the surgical treatment of many cardiac diseases possible nowadays. It temporarily takes over the function of the lungs and heart and maintains extracorporeal respiratory and circulatory support during this time. The proinflammatory cytokines become active due to contact of the blood with foreign surfaces during extracorporeal circulation [16]. The systemic inflammatory response after cardiopulmonary bypass may be limited to subclinical increase in levels of inflammatory mediators but may cause severe organ dysfunction or even death [17].

In our study, we observed that CRP, IL-6, IL-8, TNF- $\alpha$, and neutrophil elastase levels increased rapidly after CPB in both groups. IL-6, IL-8, and neutrophil elastase levels peaked at 6 hours postoperatively, whereas TNF- $\alpha$ levels tended to continuously increase in consecutive measurements up to 24 hours postoperatively. CRP levels peaked at 48 hours postoperatively in consecutive measurements. In a study of Fromes et al. evaluating the inflammatory response after $\mathrm{CPB}$ as well as in a study of Ak et al. investigating lipoprotein lipase gene polymorphism and its effects on atherosclerosis, they found that IL- 6 levels peaked at 6 hours after CPB. In this respect, we have obtained results consistent with the literature in our study $[12,18]$. In a study of Delannoy et al. investigating sepsis after $\mathrm{CPB}$ and its association with postoperative CRP and procalcitonin levels, they observed that CRP levels peaked at 24 and 48 hours after CPB [19]. This finding was similar to the CRP data we obtained in our study. In a study of Alataş et al. evaluating myocardial ischemia reperfusion injury after $\mathrm{CPB}$, they showed that TNF$\alpha$ levels tended to increase even at 24 hours postoperatively. This result was also similar to our study $[20,21]$.

When the conventional cardiopulmonary bypass and MİECT groups were compared with each other, there was no statistically significant difference between the two groups in 
TABLE 2: Perioperative data of the patients.

\begin{tabular}{|c|c|c|c|c|}
\hline & & Group C & Group M & $P$ \\
\hline Previous CABG number & $($ mean $\pm S D)$ & $3.25 \pm 0.81$ & $2.58 \pm 0.71$ & $p=0.27$ \\
\hline Duration of operation (min) & $($ mean $\pm S D)$ & $262.22 \pm 44.49$ & $240.64 \pm 40.16$ & $p=0.16$ \\
\hline Duration of CPB (min) & $($ mean $\pm \mathrm{SD})$ & $84.92 \pm 19.75$ & $85.85 \pm 20.56$ & $p=0.17$ \\
\hline Cross-clamp time(min) & $($ mean $\pm S D)$ & $35.74 \pm 11.49$ & $36.41 \pm 9.41$ & $p=0.13$ \\
\hline Prime (cc) & $($ mean $\pm S D)$ & $1603.71 \pm 49.85$ & $802.60 \pm 48.26$ & $p=0.0001$ \\
\hline Cardioplegia (cc) & $($ mean $\pm S D)$ & $898.14 \pm 169.37$ & $558.06 \pm 114.81$ & $p=0.0001$ \\
\hline Hypothermia $\left({ }^{\circ} \mathrm{C}\right)$ & $($ mean $\pm S D)$ & $31.59 \pm 1.80$ & $34.01 \pm 0.042$ & $p=0.02$ \\
\hline
\end{tabular}

CABG: coronary artery bypass grafting; $\mathrm{CPB}$ : cardiopulmonary bypass.

TABle 3: Postoperative data of the patients.

\begin{tabular}{|c|c|c|c|c|}
\hline & & Group C & Group M & $P$ \\
\hline Length of hospital stay (day) & $($ mean $\pm S D)$ & $6.59 \pm 1.42$ & $7.09 \pm 1.79$ & $P=0.45$ \\
\hline Ventilation time (hour) & $($ mean $\pm S D)$ & $10.46 \pm 1.83$ & $6.21 \pm 1.73$ & $P=0.0001$ \\
\hline ICU stay (hour) & $($ mean $\pm S D)$ & $41.77 \pm 21.66$ & $34.83 \pm 18.42$ & $P=0.25$ \\
\hline Drainage volume $(\mathrm{cc})$ & $($ mean $\pm S D)$ & $672.22 \pm 157.09$ & $446.77 \pm 134.12$ & $P=0.0001$ \\
\hline İnotrope use & $(n / \%)$ & $11 \pm 40.7 \%$ & $12 \pm 38.7 \%$ & $P=0.15$ \\
\hline Red blood cell transfusion (U) & (mean. $\pm S D)$ & $1.70 \pm 0.66$ & $0.93 \pm 0.89$ & $P=0.0001$ \\
\hline Fresh frozen plasma transfusion (U) & $($ mean $\pm S D)$ & $2.51 \pm 1.05$ & $0.93 \pm 0.20$ & $P=0.0001$ \\
\hline Platelet transfusion $(\mathrm{ml})$ & $($ mean $\pm \mathrm{SD})$ & $0.23 \pm 0.10$ & $0.22 \pm 0.10$ & $P=0.35$ \\
\hline
\end{tabular}

ICU: intensive care unit.

TABLE 4: Biochemical values of the patients.

\begin{tabular}{|c|c|c|c|c|}
\hline & & Group C & Group M & $P$ \\
\hline Hematocrit & $\begin{array}{c}\text { Preop } \\
\text { POMP OUTPUT } \\
\text { Postop- } 24^{\text {th }} \text { hour }\end{array}$ & $\begin{array}{l}37.11 \pm 4.60 \\
28.82 \pm 4.39 \\
27.64 \pm 4.27 \\
\end{array}$ & $\begin{array}{c}37.64 \pm 5.46 \\
32.71 \pm 3.98 \\
31.9 \pm 4.65 \\
\end{array}$ & $\begin{array}{c}P=0.64 \\
P=0.18 \\
P=0.001\end{array}$ \\
\hline Troponin & $\begin{array}{c}\text { Preop } \\
\text { POMP OUTPUT } \\
\text { Postop- } 24^{\text {th }} \text { hour }\end{array}$ & $\begin{array}{c}36.29 \pm 9.51 \\
323.96 \pm 84.81 \\
789.61 \pm 235.92 \\
\end{array}$ & $\begin{array}{c}26.92 \pm 5.71 \\
241.88 \pm 61.42 \\
427.55 \pm 261.29 \\
\end{array}$ & $\begin{array}{c}P=0.12 \\
P=0.53 \\
P=0.001\end{array}$ \\
\hline Creatine kinase & $\begin{array}{c}\text { Preop } \\
\text { POMP OUTPUT } \\
\text { Postop- } 24^{\text {th }} \text { hour }\end{array}$ & $\begin{array}{c}67.62 \pm 32.51 \\
317.22 \pm 107.74 \\
679.77 \pm 403.16\end{array}$ & $\begin{array}{c}92.38 \pm 52.66 \\
335.61 \pm 231.98 \\
579.06 \pm 467.60\end{array}$ & $\begin{array}{l}P=0.22 \\
P=0.26 \\
P=0.48\end{array}$ \\
\hline CK-MB & $\begin{array}{c}\text { Preop } \\
\text { POMP OUTPUT } \\
\text { Postop- } 24^{\text {th }} \text { hour }\end{array}$ & $\begin{array}{c}2.03 \pm 1.08 \\
22.05 \pm 7.56 \\
30.86 \pm 9.33\end{array}$ & $\begin{array}{c}2.25 \pm 1.90 \\
17.42 \pm 8.02 \\
20.09 \pm 5.29\end{array}$ & $\begin{array}{c}P=0.61 \\
P=0.001 \\
P=0.74\end{array}$ \\
\hline
\end{tabular}

TABle 5: C-reactive protein levels.

\begin{tabular}{|c|c|c|c|c|}
\hline & & Group C & Group M & $P$ \\
\hline \multirow{4}{*}{ CRP (C-reactive protein) } & Preop & $3.25 \pm 3.01$ & $2.64 \pm 1.70$ & $P=0.73$ \\
\hline & End-CBP & $2.54 \pm 2.43$ & $3.46 \pm 2.66$ & $P=0.63$ \\
\hline & Postop- $24^{\text {th }}$ hour & $64.49 \pm 20.24$ & $78.63 \pm 40.45$ & $P=0.1$ \\
\hline & Postop- $48^{\text {th }}$ hour & $239.22 \pm 46.05$ & $215.20 \pm 79.59$ & $P=0.25$ \\
\hline
\end{tabular}

TABLE 6: Levels of IL-6.

\begin{tabular}{|c|c|c|c|c|}
\hline & & Group C & Group M & $P$ \\
\hline \multirow{5}{*}{$\begin{array}{l}\text { IL-6 } \\
(\mathrm{pg} / \mathrm{ml})\end{array}$} & Preop & $1.69 \pm 3.74$ & $0.81 \pm 1.37$ & $P=0.47$ \\
\hline & $\mathrm{CPB} 30^{\text {th }}$ minute & $2.83 \pm 5.06$ & $1.99 \pm 4.86$ & $P=0.84$ \\
\hline & Postop- $6^{\text {th }}$ hour & $34.70 \pm 15.22$ & $32.50 \pm 18.04$ & $P=0.74$ \\
\hline & $\begin{array}{c}\text { Postop- } 24^{\text {th }} \\
\text { hour }\end{array}$ & $18.19 \pm 22.43$ & $17.20 \pm 7.88$ & $P=0.68$ \\
\hline & $\begin{array}{l}\text { Postop- } 48^{\text {th }} \\
\text { hour }\end{array}$ & $6.69 \pm 8.36$ & $9.59 \pm 7.64$ & $P=0.38$ \\
\hline
\end{tabular}

TABle 7: Levels of IL-8.

\begin{tabular}{|c|c|c|c|c|}
\hline & & Group C & Group M & $P$ \\
\hline \multirow{5}{*}{$\begin{array}{l}\text { IL-8 } \\
(\mathrm{pg} / \mathrm{ml})\end{array}$} & Preop & $21.37 \pm 26.32$ & $22.54 \pm 12.82$ & $P=0.65$ \\
\hline & $\mathrm{CPB} 30^{\text {th }}$ minute & $24.55 \pm 21.73$ & $22.80 \pm 17.11$ & $P=0.42$ \\
\hline & Postop- $6^{\text {th }}$ hour & $30.70 \pm 32.35$ & $30.00 \pm 20.91$ & $P=0.36$ \\
\hline & $\begin{array}{c}\text { Postop- } 24^{\text {th }} \\
\text { hour }\end{array}$ & $23.14 \pm 21.55$ & $22.58 \pm 14.00$ & $P=0.55$ \\
\hline & $\begin{array}{l}\text { Postop- } 48^{\text {th }} \\
\text { hour }\end{array}$ & $22.03 \pm 16.96$ & $22.29 \pm 22.85$ & $P=0.76$ \\
\hline
\end{tabular}


TABLE 8: Levels of TNF- $\alpha$.

\begin{tabular}{lcccc}
\hline & & Group C & Group M & $P$ \\
\hline & Preop & $13.79 \pm 4.79$ & $13.42 \pm 0.84$ & $12.90 \pm 9.32$ \\
TNF- $\alpha$ & CPB 30 & $14.17 \pm 5.71$ & $13.98 \pm 2.12$ & \\
$(\mathrm{pg} / \mathrm{ml})$ & Postop-6 $^{\text {th }}$ hour & $14.32 \pm 4.33$ & $14.73 \pm 4.17$ & $P=0.66$ \\
& Postop-24 $^{\text {th }}$ hour & $15.12 \pm 9.30$ & $13.87 \pm 7.49$ & $P=0.17$ \\
& Postop-48 $^{\text {th }}$ hour & $12.43 \pm 4.18$ & $P=0.49$ \\
\hline
\end{tabular}

TABLE 9: Levels of neutrophil elastase.

\begin{tabular}{|c|c|c|c|c|}
\hline & & Group C & Group M & $P$ \\
\hline \multirow{5}{*}{$\begin{array}{l}\text { Neutrophil elastase } \\
(\mathrm{pg} / \mathrm{ml})\end{array}$} & Preop & $81.4 \pm 23.34$ & $83.48 \pm 46.08$ & $P=0.35$ \\
\hline & $\mathrm{CPB} 30^{\text {th }}$ minute & $104.29 \pm 40.21$ & $108.12 \pm 66.54$ & $P=0.88$ \\
\hline & Postop- $6^{\text {th }}$ hour & $137.85 \pm 97.16$ & $152.96 \pm 136.33$ & $P=0.56$ \\
\hline & Postop- $24^{\text {th }}$ hour & $97.88 \pm 36.42$ & $107.93 \pm 49.70$ & $P=0.75$ \\
\hline & Postop- $48^{\text {th }}$ hour & $80.77 \pm 40.29$ & $81.51 \pm 59.54$ & $P=0.22$ \\
\hline
\end{tabular}

terms of mean IL- 6 , IL- 8, TNF- $\alpha$, and neutrophil elastase levels at all postoperative sampling times $(p>0.05)$.

The fact that the inflammatory parameters were similar for the two groups in our study can be explained by the fact that hypothermia was administered at a higher rate during cardiopulmonary bypass in the conventional group. Studies have shown that hypothermia is protective against the inflammatory response. Another explanation in this regard can be that cardiopulmonary bypass time is short in both groups and the inflammatory response becomes obvious, and consequently, the protective effect of MIECT does not become evident.

When we examined the effects of hypothermia on leukocyte activation, cytokine balance, and thus postoperative organ damage, Quing et al. reported that hypothermia may be beneficial in organ preservation by suppressing TNF- $\alpha$ production during cardiopulmonary bypass [22]. This idea is also supported by the fact that Menasche et al. have suggested that hypothermia administered during CPB reduces the inflammatory response with low cytokine production [23-25].

We think that the anti-inflammatory effect may become more prominent with deepening hypothermia in patients operated on with the minimal extracorporeal circulation system. On the other hand, reducing the hypothermia protocol applied during $\mathrm{CPB}$ to lower temperatures in centers using the minimal extracorporeal circulation system may also be effective in observing the suppressive effect of hypothermia on the inflammatory response.

In recent years, many studies have reported that hemodilutional anemia, which occurs during $\mathrm{CPB}$, causes organ dysfunction and increases morbidity and mortality $[26,27]$. In our study, the mean Hct value after leaving CPB was higher in patients operated on with the MIECT system. These patients had lower blood transfusion rates. It is known that blood transfusion during coronary bypass surgery reduces long-term survival rates $[28,29]$. These data continue to push perfusion technology to design circuits which allow use of a lower prime volume and have less contact surface area. In our study, the groups operated using the minimal extracorporeal circulation system and conventional cardiopulmonary bypass system were compared with each other in terms of the need for erythrocyte suspension and fresh frozen plasma transfusion and total length of stay. We observed a statistically significant decrease in these variables in the MiECT group $(p<0.05)$. In this context, minimal extracorporeal circulation has recently become popular. The fact that studies have found that markers of systemic inflammatory response are lower in patients operated on with the MIECT system has suggested that it would bring advantages in terms of mortality and morbidity. However, the long-term results of the use of the MiECT system in terms of morbidity and mortality have not yet been fully demonstrated $[30,31]$. The reasons such as the fact that the MiECT system requires a certain learning process, has a risk of perioperative venous air leakage, creates a concern for microemboli formation, and restricts surgical field aspiration limit its use. In addition, the fact that open heart operations can be performed optimally and easily with acceptable mortality and morbidity rates by conventional methods nowadays reveals the more widespread use of conventional methods. Geratti et al. found that the MIECT system significantly increased the postoperative Hct values and significantly decreased the blood transfusion requirements [31, 32]. In a study of Stadler et al., they reported that blood transfusion rates were similarly reduced by the prevention of intraoperative hemodilution [33]. In a study of Severdija et al. using the retrograde autologous priming method in standard cardiopulmonary bypass systems, the retrograde autologous priming method yielded a nearly twofold gain in prime volume. This gain in the same study has been shown to increase intraoperative Hct levels and to reduce the need for blood transfusion in the patients [34]. In a study conducted by Ohata et al., hematocrit values were assessed during and after cardiopulmonary bypass. They showed that hematocrit values were significantly higher in the group using the MIECT circuit [35].

In our study, we evaluated the effect of modified cardiopulmonary bypass system (i.e., use of minimal extracorporeal circulation system) on postoperative transfusion requirement and systemic inflammatory response. In our study, the molecules (IL-6, IL-8, TNF- $\alpha$, neutrophil elastase, 
and CRP), which we think to be indicative of the severity of the systemic inflammatory response, were used in patients who had similar demographic characteristics and had similar cross-clamp time and CPB duration. In our study, it was observed that the mean blood plasma concentrations of these molecules in the samples taken at different times preoperatively and postoperatively were significantly increased after CPB. When the mean postoperative values of these molecules were compared between the two groups, there was no statistically significant difference in both groups except for IL-6 value at 6 hours postoperatively, TNF- $\alpha$ value at 48 hours postoperatively, and neutrophil elastase value at $30 \mathrm{~min}$ of $\mathrm{CPB}$. The fact that the mean postoperative values of IL-6, IL- 8 , TNF- $\alpha$, neutrophil elastase, and CRP did not differ significantly between the two groups despite the application of different hypothermia protocols in the two groups at all sampling times promises possible gains for the future. The most significant difference found in our study was that the prime volume and bloodsurface contact area were reduced with the use of minimal extracorporeal circulation system. This difference significantly increased the intraoperative and postoperative $\mathrm{Hct}$ values as well as significantly reduced the need for postoperative erythrocyte suspension and fresh frozen plasma transfusion in the group using the minimal extracorporeal circulation system.

Our study had some weak points. It was conducted in a small number of patients and in a single center. The surgical interventions were compatible because all patients were operated by the same surgical team and the same anesthesia team. However, there were a small number of patients. Retrograde autologous priming could not be made in the group using conventional $\mathrm{CPB}$ system in accordance with routine practice in our clinic. The cardioplegia protocol differed between the two groups. The number of patients participating in the study was not sufficient to examine the cause-effect relationship for postoperative complications such as chronic renal failure (CRF), cerebrovascular event, myocardial infarction, and mortality. The study included relatively low-risk patients who had normal preoperative ejection fraction, who had normal preoperative kidney and liver functions, and who had no chronic disease and were negative for inflammatory markers. From the fact that open heart operations can be performed with low morbidity and mortality rates by standard methods in a group of low-risk patients, it can be considered that more valuable gains can be obtained in a group of high-risk patients. In this context, it can be considered that this study should also be performed in a group of high-risk patients, in long-term and more complex operations, in patients with chronic renal failure, or in patients with preoperative left ventricular dysfunction.

As a result, our study demonstrated that minimal extracorporeal circulation system allowed use of a lower prime volume, reducing intraoperative hemodilution and the need for postoperative blood transfusion. However, we found that there was no statistically significant difference between minimal extracorporeal circulation system and conventional cardiopulmonary bypass system in terms of inflammatory response. Minimal extracorporeal circulation systems can bring advantages in the reduction of systemic inflammatory response by establishing lower temperatures during cardiopulmonary bypass and by utilizing the positive effects of hypothermia on the inflammatory response.

\section{Data Availability}

The data used to support the findings of this study are available from the corresponding author upon request.

\section{Conflicts of Interest}

The authors declare that they have no conflicts of interest.

\section{References}

[1] G. J. Moore, A. Pfister, and G. D. Trachiotis, "Outcomes for off-pump coronary artery bypass grafting in high-risk groups: a historical perspective," Heart Surgery Forum, vol. 8, no. 1, p. 19, 2005.

[2] M. Polomsky, X. He, S. M. O’Brien, and J. D. Puskas, "Outcomes of off-pump versus on-pump coronary artery bypass grafting: impact of preoperative risk," Journal of Thoracic and Cardiovascular Surgery, vol. 145, no. 5, pp. 1193-1198, 2013.

[3] H. Bayram, D. Erer, E. Iriz, M. H. Zor, O. Gulbahar, and M. Ozdogan, "Comparison of the effects of pulsatile cardiopulmonary bypass, non-pulsatile cardiopulmonary bypass and off-pump coronary artery bypass grafting on the respiratory system and serum carbonyl," Perfusion, vol. 27, no. 5, pp. 378-385, 2012.

[4] M. Zakkar, R. Ascione, A. F. James, G. D. Angelini, and M. S. Suleiman, "Inflammation, oxidative stress and postoperative atrial fibrillation in cardiac surgery," Pharmacology \& Therapeutics, vol. 154, pp. 13-20, 2015.

[5] A. Kahraman, E. Mutlu, and M. Aldağ, "ADMA, SDMA and L-arginine may be novel targets in pharmacotherapy for complications due to cardiopulmonary bypass," Journal of Medical Biochemistry, vol. 36, no. 1, 2017.

[6] M. Polomsky, X. He, S. M. O'Brien, and J. D. Puskas, "Outcomes of off-pump versus on-pump coronary artery bypass grafting: impact of preoperative risk," Journal of Thoracic and Cardiovascular Surgery, vol. 145, no. 5, pp. 1193-1198, 2013.

[7] E. Tamayo, F. J. Álvarez, O. Alonso et al., “The inflammatory response to colloids and crystalloids used for pump priming during cardiopulmonary bypass," Acta Anaesthesiologica Scandinavica, vol. 52, no. 9, pp. 1204-1212, 2008.

[8] B. Keeling, V. Thourani, G. Aliawadi et al., "Conversion from off-pump coronary artery bypass grafting to on-pump coronary artery bypass grafting," Annals of Thoracic Surgery, vol. 104, no. 4, pp. 1267-1274, 2017.

[9] M. Valtonen, T. Vähäsilta, T. Kaila-Keinänen, and K. Kuttila, "New mini-extracorporeal circulation system (ECC.O) is a safe technique in coronary surgery," Scandinavian Cardiovascular Journal, vol. 41, no. 5, pp. 345-350, 2007.

[10] M. Hilker, A. Philipp, O. Husser et al., "Extracorporeal life support during PCI and TAVI procedures using Mini-ECMO systems," Thoracic and Cardiovascular Surgeon, vol. 60, 2012.

[11] W. B. Keeling, P. D. Kilgo, J. D. Puskas et al., "Off-pump coronary artery bypass grafting attenuates morbidity and mortality for patients with low and high body mass index," 
Journal of Thoracic and Cardiovascular Surgery, vol. 146, no. 6, pp. 1442-1448, 2013.

[12] Y. Fromes, D. Gaillard, O. Ponzio et al., "Reduction of the inflammatory response following coronary bypass grafting with total minimal extracorporeal circulation," European Journal of Cardio-Thoracic Surgery, vol. 22, no. 4, pp. 527-533, 2002.

[13] T. Ohata, M. Mitsuno, M. Yamamura et al., "Minimal cardiopulmonary bypass attenuates neutrophil activation and cytokine release in coronary artery bypass grafting," Journal of Artificial Organs, vol. 10, no. 2, pp. 92-95, 2007.

[14] T. Kofidis, H. Baraki, H. Singh et al., "The minimized extracorporeal circulation system causes less inflammation and organ damage," Perfusion, vol. 23, no. 3, pp. 147-151, 2008.

[15] T. Wittwer, A. Sabashnikov, P. B. Rahmanian et al., "Less invasive coronary artery revascularization with a minimized extracorporeal circulation system: preliminary results of a comparative study with off-pump-procedures," Journal of Cardiothoracic Surgery, vol. 8, no. 1, p. 75, 2013.

[16] P. R. de Jong, A. W. L. Schadenberg, T. van den Broek et al., "STAT3 regulates monocyte TNF-alpha production in systemic inflammation caused by cardiac surgery with cardiopulmonary bypass," PLoS One, vol. 7, no. 4, Article ID e35070, 2012.

[17] J. Cremer, M. Martin, H. Redl et al., "Systemic inflammatory response syndrome after cardiac operations," Annals of Thoracic Surgery, vol. 61, no. 96, pp. 1714-1720, 1996.

[18] K. Ak, S. İsbir, A. Tekeli et al., "Presence of lipoprotein lipase S447X stop codon affects the magnitude of interleukin 8 release after cardiac surgery with cardiopulmonary bypass," Journal of Thoracic and Cardiovascular Surgery, vol. 134, no. 2, pp. 477-483, 2007.

[19] B. Delannoy, M.-L. Guye, D. Slaiman, J.-J. Lehot, and M. Cannesson, "Effect of cardiopulmonary bypass on activated partial thromboplastin time waveform analysis, serum procalcitonin and C-reactive protein concentrations," Critical Care, vol. 13, no. 6, p. R180, 2009.

[20] Ö. Alataş, Ö. Çolak, B. Büyükkidan, O. Portakal, and B. Tanriverdi, "Soluble interleukin-2 receptor and interleukin8 plasma levels during and after cardiopulmonary bypass: correlations with creatine kinase and creatine kinase MB," Clinical and Experimental Medicine, vol. 1, no. 1, pp. 13-18, 2001.

[21] X. L. Yang, D. Wang, G. Y. Zhang, and X. L. Guo, "Comparison of the myocardial protective effect of sevoflurane versus propofol in patients undergoing heart valve replacement surgery with cardiopulmonary bypass," $B M C$ Anesthesiology, vol. 17, no. 1, 2017.

[22] M. Qing, J. F. Vazquez-Jimenez, B. Klosterhalfen et al., "Influence of temperature during cardiopulmonary bypass on leukocyte activation, cytokine balance, and post-operative organ damage," Shock, vol. 15, no. 5, pp. 372-377, 2001.

[23] P. Menasche, S. Haydar, J. Peynet et al., "A potential mechanism of vasodilation after warm heart surgery. The temperature-dependent release of cytokines," Thoracic and Cardiovascular Surgeon, vol. 107, no. 1, pp. 293-299, 1994.

[24] F. Le Deist, P. Menasché, C. Kucharski, A. Bel, A. Piwnica, and G. Bloch, "Hypothermia during cardiopulmonary bypass delays but does not prevent neutrophil-endothelial cell adhesion. A clinical study," Circulation, vol. 92, no. 9, pp. II354-II358, 1995.

[25] M. Liu, B. T. Galen, and L. Kruge, "The perfect storm: fever, tachycardia, and altered mental status after PTCA," Journal of General Internal Medicine, vol. 31, no. 2, p. S756, 2016.
[26] R. H. Habib, A. Zacharias, T. A. Schwann, C. J. Riordan, S. J. Durham, and A. Shah, "Adverse effects of low hematocrit during cardiopulmonary bypass in the adult: should current practice be changed?," Journal of Thoracic and Cardiovascular Surgery, vol. 125, no. 6, pp. 1438-1450, 2003.

[27] W. C. Fang, R. E. Helm, K. H. Krieger et al., "Impact of minimum hematocrit during cardiopulmonary bypass on mortality in patients undergoing coronary artery surgery," Circulation, vol. 96, no. 9, pp. 194-199, 1997.

[28] M. C. Engoren, R. H. Habib, A. Zacharias, T. A. Schwann, C. J. Riordan, and S. J. Durham, "Effect of blood transfusion on long-term survival after cardiac operation," Annals of Thoracic Surgery, vol. 74, no. 4, pp. 1180-1186, 2002.

[29] M. Kuduvalli, A. Oo, N. Newall et al., "Effect of peri-operative red blood cell transfusion on 30-day and 1-year mortality following coronary artery bypass surgery," European Journal of Cardio-thoracic Surgery, vol. 27, no. 4, pp. 592-598, 2005.

[30] K. Anastasiadis, P. Antonitsis, A.-B. Haidich, H. Argiriadou, A. Deliopoulos, and C. Papakonstantinou, "Use of minimal extracorporeal circulation improves outcome after heart surgery; a systematic review and meta-analysis of randomized controlled trials," International Journal of Cardiology, vol. 164, no. 2, pp. 158-169, 2013.

[31] J.-P. Remadi, P. Marticho, I. Butoi et al., "Clinical experience with the mini-extracorporeal circulation system: an evolution or a revolution?," Annals of Thoracic Surgery, vol. 77, no. 6, pp. 2172-2175, 2004.

[32] W. B. Gerritsen, W. J. van Boven, R. M. Wesselink et al., "Significant reduction in blood loss in patients undergoing minimal extracorporeal circulation," Transfusion Medicine, vol. 16 , no. 5, pp. 329-334, 2006.

[33] M. Stalder, E. Gygax, F. F. Immer, L. Englberger, H. Tevaearai, and T. P. Carrel, "Minimized cardiopulmonary bypass combined with a smart suction device: the future of cardiopulmonary bypass?," Heart Surgery Forum, vol. 10, no. 3, pp. 170-173, 2007.

[34] E. E. Severdija, J. H. Heijmans, M. Theunissen, J. G. Maessen, P. H. Roekaerts, and P. W. Weerwind, "Retrograde autologous priming reduces transfusion requirements in coronary artery bypass surgery," Perfusion, vol. 26, no. 4, pp. 315-21, 2011.

[35] T. Ohata, M. Mitsuno, M. Yamamura et al., "Beneficial effects of mini-cardiopulmonary bypass on hemostasis in coronary artery bypass grafting: analysis of inflammatory response and hemodilution," ASAIO Journal, vol. 54, no. 2, pp. 207-209, 2008. 


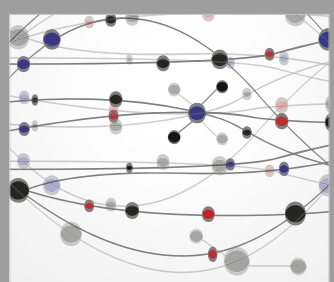

The Scientific World Journal
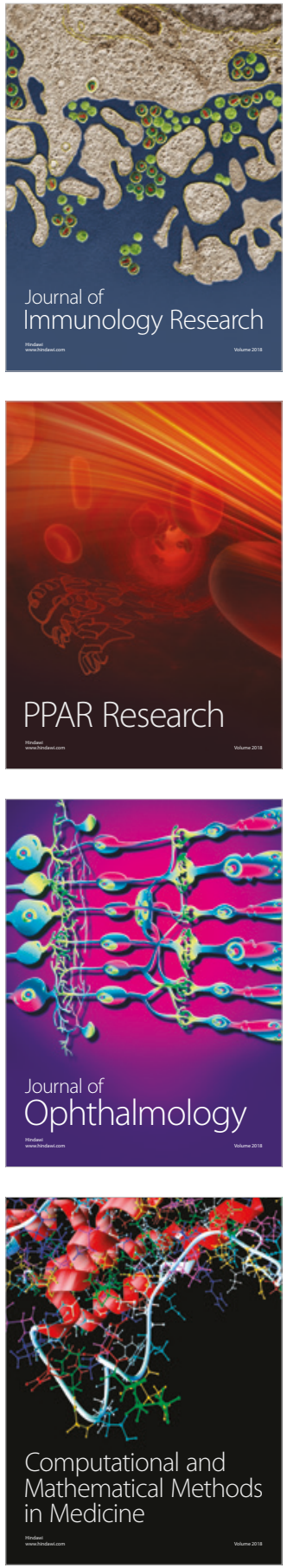

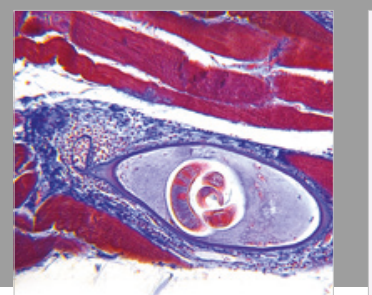

Gastroenterology Research and Practice

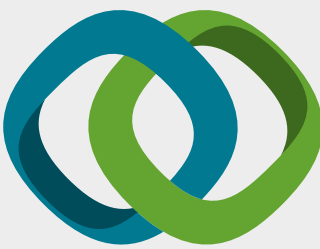

\section{Hindawi}

Submit your manuscripts at

www.hindawi.com
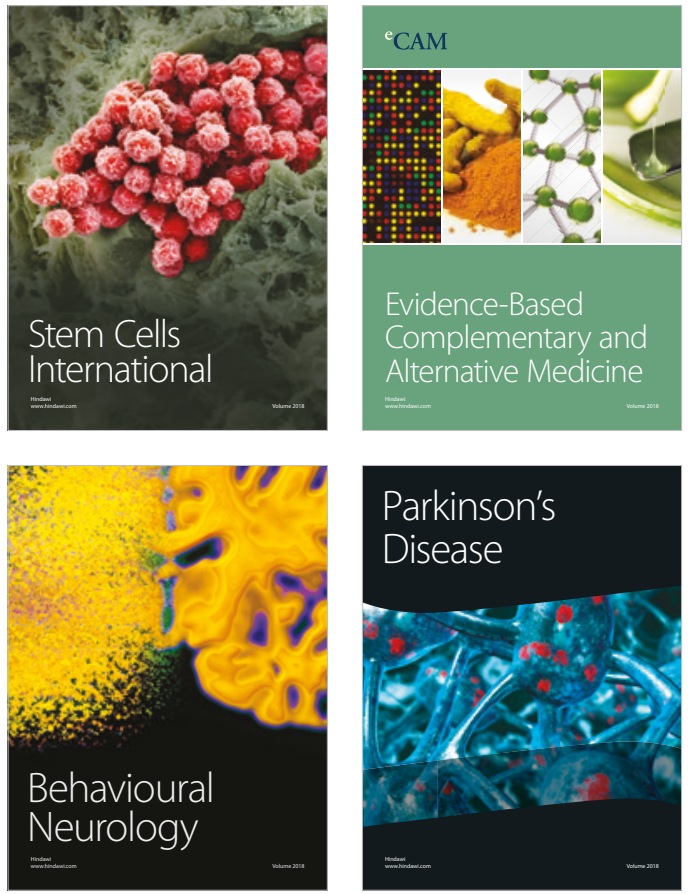

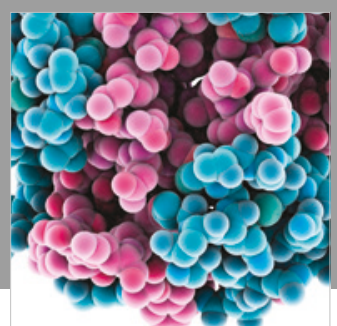

ournal of

Diabetes Research

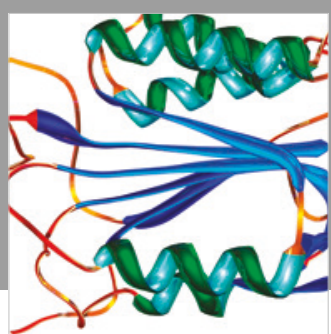

Disease Markers
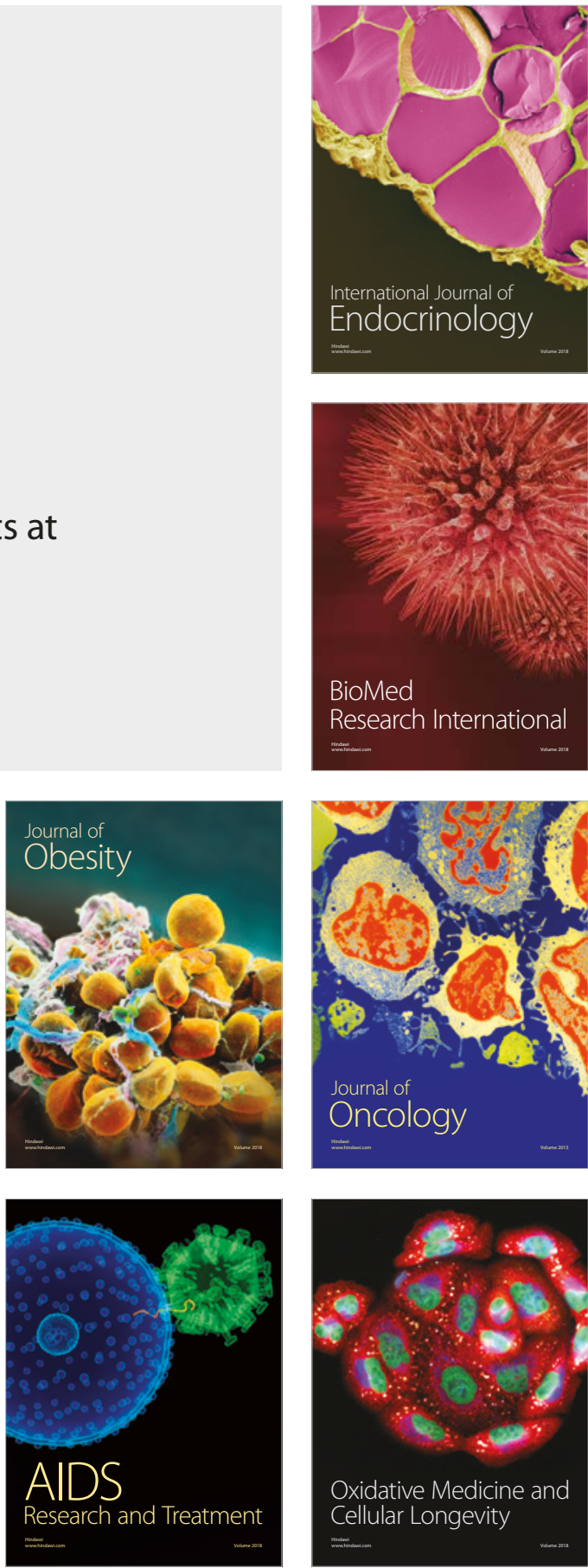